\title{
Frequency and predictors of the lupus low disease activity state in a multi-national and multi-ethnic cohort
}

Vera Golder ${ }^{1 *}$ (D), Rangi Kandane-Rathnayake ${ }^{1}$, Alberta Yik-Bun Hoi ${ }^{1}$, Molla Huq ${ }^{2}$, Worawit Louthrenoo ${ }^{3}$, Yuan $\mathrm{An}^{4}$, Zhan Guo Li $i^{4}$, Shue Fen Luo ${ }^{5}$, Sargunan Sockalingam ${ }^{6}$, Chak Sing Lau', Alfred Lok Lee ${ }^{7}$, Mo Yin Mok Aisha Lateef ${ }^{8}$, Kate Franklyn ${ }^{1}$, Susan Morton ${ }^{9}$, Sandra Teresa V. Navarra ${ }^{10}$, Leonid Zamora ${ }^{10}$, Yeong-Jian Wu W $^{5}$ Laniyati Hamijoyo $^{11}$, Madelynn Chan ${ }^{12}$, Sean O'Neill ${ }^{13}$, Fiona Goldblatt ${ }^{14}$, Eric Francis Morand ${ }^{1 \dagger}$, Mandana Nikpour ${ }^{2+}$ and for the Asia-Pacific Lupus Collaboration

\begin{abstract}
Background: Systemic lupus erythematosus (SLE) is a chronic heterogeneous disease with considerable burden from disease activity and damage. A novel clinical treatment target in the form of the lupus low disease activity state (LLDAS) has been recently reported, with retrospective validation showing that time spent in LLDAS translates to reduced damage accrual. The objectives of this study were to describe the frequency and identify the predictors of attaining LLDAS in a large multinational cohort of patients with SLE.
\end{abstract}

Methods: Data were collected at the recruitment visit in patients with SLE enrolled in a longitudinal study in nine countries. Data were analysed cross-sectionally against the recently published definition of LLDAS, and the frequency and characteristics associated with presence of LLDAS were determined. Stepwise multivariable logistic regression was used to determine predictors of LLDAS.

Results: Of the 1846 patients assessed, criteria for LLDAS were met by $44 \%$. Patients with shorter disease duration were less likely to be in LLDAS (OR $0.31,95 \% \mathrm{Cl} 0.19-0.49, p<0.001)$. Likewise, patients with a history of discoid rash (OR 0.66, $95 \% \mathrm{Cl} 0.49-0.89, p=0.006$ ), renal disease (OR 0.60, $95 \% \mathrm{Cl} 0.48-0.75, p<0.001)$, elevated double stranded DNA (OR 0.65, $95 \%$ Cl 0.53-0.81, $p<0.001$ ) or hypocomplementaemia (OR 0.52, $95 \%$ Cl 0.40-0.67, $p<0.001$ ) were less likely to be in LLDAS. When countries were compared, higher national social wealth (OR 1.57, $95 \% \mathrm{Cl} 1.25-1.98, p<0.001)$ as measured by the gross domestic product per capita was positively associated with LLDAS, but ethnicity was not.

Conclusion: The lupus low disease activity state is observed in less than half of patients with SLE at a single point in time. Disease duration and phenotype, and national social wealth, are predictive of LLDAS.

Keywords: Systemic lupus erythematosus, Disease activity, Treatment target, Low disease activity

\section{Background}

Systemic lupus erythematosus (SLE) is a chronic multiorgan autoimmune disease with a broad spectrum of manifestations. Despite global advances in translational research, effective targeted therapies in SLE are lacking [1], and a large proportion of patients are treated with

\footnotetext{
* Correspondence: vera.golder@monash.edu; vera.golder@gmail.com

${ }^{\dagger}$ Equal contributors

${ }^{1}$ Monash University, Melbourne, Australia

Full list of author information is available at the end of the article
}

long-term glucocorticoids and non-specific immunosuppressants, which fail to prevent significant morbidity and reduction in life expectancy [2]. The course of SLE is variable, in some cases characterized by periods of relative inactivity punctuated by disease flare, whilst others have persistently active disease [3]. Current instruments used to measure disease activity are complex [4], contributing to mixed results in clinical trials of new targeted therapies [5]. This state of affairs has lead to a call for definitions of treatment target states that can be used in clinical trials and clinical practice [6]. 
Given that definitions of remission remain under debate [7], and a recently reported stringent definition of remission occurs in only $2 \%$ of patients with SLE [8], using remission as a treatment target is not pragmatic. In other autoimmune diseases, mainly rheumatoid arthritis (RA), achieving a minimally active disease state has been proven to translate into improved patient outcomes [9]. The value of a treatment target for SLE has been recently described in an international consensus statement, in which defining a low disease activity state to use as a treatment target was set as a research agenda [10].

Using consensus methods, the Asia-Pacific Lupus Collaboration has recently developed and retrospectively validated the lupus low disease activity state (LLDAS) definition [11]. The conceptual definition of LLDAS is a state, which if sustained, is associated with good longterm outcomes. The operational definition of LLDAS is fulfilled when all of the following criteria are met: (1) SLE Disease Activity Index (SLEDAI-2 K) $\leq 4$, with no activity in major organ systems (renal, central nervous system (CNS), cardiopulmonary, vasculitis, fever) and no haemolytic anaemia or gastrointestinal activity; (2) no new features of lupus disease activity compared to the previous assessment; (3) a Safety of Estrogens in Lupus Erythematosus National Assessment (SELENA)-SLEDAI physician global assessment (PGA) (scale $0-3$ ) $\leq 1$; (4) a current prednisolone (or equivalent) dose $\leq 7.5 \mathrm{mg}$ daily; and (5) well-tolerated standard maintenance doses of immunosuppressive drugs and approved biologic agents, excluding investigational drugs. In a retrospective cohort analysis, Franklyn et al. showed that patients who spent greater than $50 \%$ of their disease duration in LLDAS accrued significantly less damage compared to patients who did not [11], suggesting this definition has a role in the identification of treatment responses associated with improved long-term outcomes.

Currently, work is underway to prospectively validate and refine this definition of LLDAS in a large multinational cohort followed over several years, with the hypothesis that attainment of LLDAS results in less damage accrual. The objective of the current study is to determine the frequency and correlates of LLDAS in a cross-sectional analysis of data collected at recruitment for this study.

\section{Methods}

\section{Study population}

Patients were recruited at 12 centres in nine countries, commencing in May 2013. Each institution obtained ethics approval and written informed patient consent for the study. Patients over the age of 18 years who fulfilled criteria for SLE (either the 1997 American College of Rheumatology (ACR) criteria [12] or the 2012 Systemic
Lupus International Collaborating Clinics (SLICC) criteria [13]) were eligible. Data collection took place during the routine ambulatory care of each SLE patient, using a standardized paper or electronic case report form.

\section{Variables}

At recruitment, demographics, disease characteristics and clinical variables were collected from each patient. Demographic variables included gender, ethnicity (selfreport based on Australian Standard Classification of Cultural and Ethnic Groups [14]), date of birth, year of definite SLE diagnosis, smoking status, and highest attained education level. Disease manifestations were determined from the ACR classification criteria on an "ever present" basis. Current use and doses of glucocorticoids and immunosuppressive medications were captured for each patient. Disease activity was measured using SLEDAI-2 K [15], and a PGA on a scale of $0-3$. Disease flares compared to the previous routine clinical visit were captured using the SLE flare index (SFI) [16]. Irreversible disease damage was captured using the SLICC damage index (SLICC-DI) [17]. Additionally, laboratory results for each patient were obtained within 30 days of the visit, including full blood count, renal function and electrolytes, serum albumin, urine protein/ creatinine ratio and microscopy, erythrocyte sedimentation rate, complement 3 and 4, and double stranded DNA (dsDNA) antibody titre.

\section{Determination of LLDAS}

A patient was considered to be in LLDAS if they fulfilled all five predefined criteria [11], with the following modifications. Given the cross-sectional nature of the baseline visit, data collected at recruitment, and hence the absence of data from the previous visit, patients were deemed to be on stable doses of immunosuppressive medications if they did not exceed the maximum recommended dose (Table 3); the criterion for "no new disease activity" was deemed to be met if patients did not meet any SFI criteria.

\section{Data analysis}

Given the young mean age of the patients (Table 1), age at diagnosis $\leq 30$ years was used as a binary variable. Given the likelihood of higher disease activity in the period immediately after diagnosis of SLE [18], disease duration $\leq 1$ year was also used as a binary variable. Patients from different countries were grouped according to gross domestic product (GDP) purchasing power parity per capita [19] in order to account for international differences in socioeconomic status.

Pooled data from all sites were analysed using STATA v13 (StataCorp, College Station, TX, USA). Data are 
Table 1 Patient demographics and disease characteristics

\begin{tabular}{|c|c|}
\hline & $\begin{array}{l}\text { Number }(\%)^{c} \text { or mean (SD) } \\
\text { or median (IQR 25-75) } \\
\text { ( } n=1846 \text { patients) }\end{array}$ \\
\hline \multicolumn{2}{|l|}{ Country } \\
\hline Australia & $240(13.00 \%)$ \\
\hline China & $235(12.73 \%)$ \\
\hline Hong Kong & $190(10.29 \%)$ \\
\hline Indonesia & $98(5.31 \%)$ \\
\hline Malaysia & $193(10.46 \%)$ \\
\hline Philippines & $124(6.72 \%)$ \\
\hline Singapore & $221(11.97 \%)$ \\
\hline Taiwan & $295(15.98 \%)$ \\
\hline Thailand & $250(13.54 \%)$ \\
\hline \multicolumn{2}{|l|}{ Ethnicity } \\
\hline Caucasian & $126(6.73 \%)$ \\
\hline Chinese & 1008 (54.60 \%) \\
\hline Filipino & $132(7.15 \%)$ \\
\hline Indonesian & $102(5.53 \%)$ \\
\hline Thai & $255(13.81 \%)$ \\
\hline Malay & 98 (5.31\%) \\
\hline Vietnamese/Cambodian & $24(1.30 \%)$ \\
\hline Indian/Sri Lankan & $64(3.47 \%)$ \\
\hline Other $^{a}$ & $37(2.00 \%)$ \\
\hline Female gender & $1723(93.34 \%)$ \\
\hline Age at diagnosis (years) & $29.34(12.35)$ \\
\hline Age at diagnosis $\leq 30$ years & $973(52.71 \%)$ \\
\hline Disease duration at enrollment (years) & $8.64(8.50)$ \\
\hline Disease duration at enrollment $\leq 1$ year & $149(8.07 \%)$ \\
\hline Current smoker & $67(3.63 \%)$ \\
\hline First-degree relative with SLE & $117(6.34 \%)$ \\
\hline \multicolumn{2}{|l|}{ Highest attained education level } \\
\hline Primary & $242(13.11 \%)$ \\
\hline Secondary & 572 (30.99 \%) \\
\hline Tertiary & 618 (33.48 \%) \\
\hline \multicolumn{2}{|l|}{ ACR criteria $^{b}$} \\
\hline Malar rash & 1087 (58.88 \%) \\
\hline Discoid rash & 290 (15.71\%) \\
\hline Photosensitivity & 537 (29.09 \%) \\
\hline Mouth ulcers & 670 (36.29 \%) \\
\hline Arthritis & 1205 (65.28 \%) \\
\hline Serositis & 313 (16.96 \%) \\
\hline Renal & 803 (43.50 \%) \\
\hline Neurologic & $160(8.67 \%)$ \\
\hline Haematologic & 1118 (60.56 \%) \\
\hline Immunologic & 1547 (83.80 \%) \\
\hline
\end{tabular}

Table 1 Patient demographics and disease characteristics (Continued)

\begin{tabular}{|c|c|}
\hline ANA & $1627(88.14 \%)$ \\
\hline Number of ACR criteria for SLE & $5.07(1.39)$ \\
\hline Number of SLICC criteria for SLE & $5.70(2.47)$ \\
\hline SLICC-DI score at enrollment & $0(0-1)$ \\
\hline Damage present at enrollment ${ }^{d}$ & $694(37.59 \%)$ \\
\hline PGA at enrollment & $0.6(0.3-1)$ \\
\hline Mild flare since last clinical review & $210(11.38 \%)$ \\
\hline Severe flare since last clinical review & $111(5.94 \%)$ \\
\hline SLEDAI-2 K score & $4(2-6)$ \\
\hline SLEDAI-2 K no complement or dsDNA & $0(0-4)$ \\
\hline \multicolumn{2}{|c|}{ 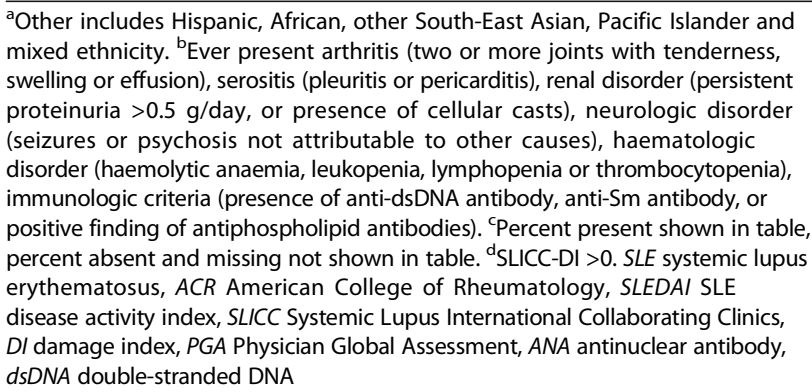 } \\
\hline
\end{tabular}

reported as mean (standard deviation (SD)) for normally distributed continuous variables and median (interquartile range (IQR)) for skewed continuous data. The chisquared test was used for categorical comparisons. Univariate simple logistic regression was used to identify predictors of LLDAS. Variables with $p$ value $\leq 0.2$ in simple logistic regression analysis were then checked for confounding and multicollinearity, prior to inclusion in stepwise multivariable logistic regression analysis for LLDAS. Model properties including sensitivity and specificity, receiver operating characteristic (ROC) and $p$ value for the Hosmer-Lemeshaw test for goodness of fit are available in Additional file 1: Table S1.

\section{Results}

Demographics and disease characteristics

A total of 1846 patients were recruited. In this cohort, $93 \%$ of patients were female, with a mean age at diagnosis of 29 ( $\mathrm{SD} \pm 12.4$ ) years and mean disease duration of $8.6(\mathrm{SD} \pm 8.5)$ years at the time of recruitment. There were 149 patients $(8 \%)$ recruited within 12 months of disease diagnosis. More than $50 \%$ of patients were of Chinese ethnicity, $7 \%$ of patients were Caucasian, and the remainder represented other ethnic groups native to the region (Table 1). Other baseline demographics are presented in Table 1.

Disease manifestations were determined from the ACR criteria on an "ever present" basis (Table 1). More than half of the patients had a history of malar rash, arthritis and haematologic and immunologic 
manifestations, and 803 patients (44\%) had a history of renal disease. The median SLEDAI-2 $\mathrm{K}$ at enrollment was 4 (IQR 2-6) (Table 1). There were 694 patients (38\%) had irreversible damage at recruitment (SLICC-DI $>0$ ), and the median SLICC-DI score was 0 (IQR 0-1). In total, 1430 patients (77.5\%) were on prednisolone, with a mean dose of $11 \mathrm{mg}$ (SD $\pm 12.8 \mathrm{mg}$ ) per day (Table 2).

\section{Frequency of meeting criteria for LLDAS}

All of the patients fulfilled at least one criterion of LLDAS (Table 3). The most frequently present criterion ( $n=1838$ patients $(99.6 \%)$ ) was the criterion relating to immunosuppressive medications, with only eight patients exceeding a maximum recommended dose. The least frequently present criterion (1171 patients (63.4\%)) was SLEDAI-2 $\mathrm{K} \leq 4$ without activity in a major organ system, followed by the glucocorticoid dose criterion (68.2\%). A higher proportion of patients achieved PGA $\leq 1$ than achieved SLEDAI $\leq 4$ ( $76 \%$ vs. $63 \%, p<0.001)$. Despite a high frequency of attainment of individual criteria, only 810 patients (43.9 \%) fulfilled all five criteria for LLDAS.

\section{Determinants of presence of LLDAS}

Multiple independent variables had a significant association with LLDAS in univariate analysis (Table 4). Younger age at diagnosis (OR 0.77, 95 \% CI 0.64$0.93, p=0.006)$ and shorter disease duration (OR 0.34, $95 \%$ CI $0.23-0.51, p<0.001)$ were negatively associated with LLDAS. A history of discoid rash (OR 0.73, $95 \%$ CI $0.57-0.95, p=0.02$ ) or renal disease (OR $0.63,95 \%$ CI $0.53-0.77, p<0.001$ ), or current anti-
dsDNA positivity (OR $0.55,95 \%$ CI $0.46-0.68, p<$ 0.001 ) and hypocomplementaemia (low $\mathrm{C} 3$ and or C4; OR $0.45,95 \%$ CI $0.37-0.55, p<0.001$ ) were all negatively associated with LLDAS. No significant differences were observed in ethnicity, gender or educational level. In multivariable logistic regression analysis, variables that remained significantly negatively associated with LLDAS included disease duration $\leq 1$ year (OR 0.31, 95 \% CI 0.19$0.49, p<0.001$ ), history of discoid rash (OR $0.66,95 \% \mathrm{CI}$ $0.49-0.89, p=0.006)$ or renal disease (OR 0.60, $95 \% \mathrm{CI}$ $0.48-0.75, p<0.001)$; and current elevated anti-dsDNA (OR $0.65,95 \%$ CI $0.53-0.81, p<0.001$ ) or hypocomplementaemia (OR 0.52, $95 \%$ CI $0.40-0.67, p<0.001$ ). Patients from countries with a high GDP (PPP) per capita were significantly more likely to be in LLDAS than patients from countries with a lower GDP (PPP) per capita (OR 1.57, $95 \%$ CI 1.25-1.98, $p<0.001$ ). Model properties for the aforementioned variables are presented in Additional file 1: Table S1.

Analysis of the effect of disease manifestations as defined by ACR criteria [12] on individual LLDAS criteria (Additional file 1: Table S2) revealed that patients with immunologic manifestations were less likely to have SLEDAI-2 K $\leq 4$ (OR 0.73, $95 \%$ CI $0.56-0.96, p=0.02$ ). A history of renal disease was significantly associated with lower odds of meeting any of the individual LLDAS criteria. The presence of damage (SLICC-DI $>0$ ) at recruitment was significantly associated with lower frequency of meeting several LLDAS criteria including SLEDAI $\leq 4$ (OR $0.79,95 \%$ CI $0.65-0.96, p=0.02)$, absence of flare (OR 0.67, $95 \%$ CI $0.52-0.88, p=0.003$ ) and PGA $\leq 1$ (OR 0.64, 95 \% CI 0.51-0.79, $p<0.001$ ).

Table 2 Medication taken at enrollment

\begin{tabular}{llll}
\hline Medication & Number (\%) & Mean dose (SD) & Dose range \\
\hline Prednisolone & $1430(77.46 \%)$ & $11.08 \mathrm{mg}(12.78)$ & $0.50-200 \mathrm{mg}$ \\
Antimalarial & $1333(72.21 \%)$ & $291.19 \mathrm{mg}(104.56)^{\mathrm{a}}$ & $28.57-600 \mathrm{mg}^{\mathrm{a}}$ \\
Methotrexate & $75(4.06 \%)$ & $13.79 \mathrm{mg}(6.73)$ & $2.50-50 \mathrm{mg}$ \\
Azathioprine & $412(22.32 \%)$ & $73.99 \mathrm{mg}(30.29)$ & $12.50-200 \mathrm{mg}$ \\
Mycophenolate mofetil & $306(16.58 \%)$ & $1247.70 \mathrm{mg}(546.96)$ & $50-3000 \mathrm{mg}$ \\
Mycophenolic acid & $41(2.22 \%)$ & $1102.93 \mathrm{mg}(645.86)$ & $180-2160 \mathrm{mg}$ \\
Leflunomide $_{\text {Cyclosporine }}$ & $38(2.06 \%)$ & $15.53 \mathrm{mg}(5.49)$ & $10-30 \mathrm{mg}$ \\
Cyclophosphomide $^{\mathrm{b}}$ & $35(1.90 \%)$ & $126.43 \mathrm{mg}(65.29)$ & $50-300 \mathrm{mg}$ \\
Rituximab $^{\mathrm{b}}$ & $73(3.95 \%)$ & $\mathrm{N} / \mathrm{A}$ & $\mathrm{N} / \mathrm{A}$ \\
Belimumab $^{\mathrm{b}}$ & $13(0.70 \%)$ & $\mathrm{N} / \mathrm{A}$ & $\mathrm{N} / \mathrm{A}$ \\
Any Immunosuppressant $^{\mathrm{c}}$ & $15(0.81 \%)$ & $\mathrm{N} / \mathrm{A}$ & $\mathrm{N} / \mathrm{A}$ \\
\hline
\end{tabular}

${ }^{\mathrm{a}}$ Based on hydroxychloroquine dosing - Indonesia and Thailand predominantly use chloroquine. ${ }^{\mathrm{b}}$ Taken in the last 6 months. ${ }^{\mathrm{C}}$ Either methotrexate, azathioprine, mycophenolate, leflunomide, cyclosporine, cyclophosphamide, rituximab and/or belimumab. Maximum recommended dose: hydroxychloroquine $\leq 400$ mg; methotrexate $\leq 30 \mathrm{mg}$; azathioprine $\leq 200 \mathrm{mg}$; mycophenolate mofetil $\leq 3000 \mathrm{mg}$; mycophenolic acid $\leq 2160 \mathrm{mg}$; leflunomide $\leq 20 \mathrm{mg}$ N/A - dosing not applicable 
Table $\mathbf{3}$ Lupus low disease activity state (LLDAS) frequency

\begin{tabular}{|c|c|}
\hline Descriptors of disease activity & $\begin{array}{l}\text { Number }(\%) \\
(n=1846)\end{array}$ \\
\hline $\begin{array}{l}\text { 1. SLEDAI-2 K } \leq 4 \text {, with no activity in major } \\
\text { organ systems (renal, CNS, cardiopulmonary, } \\
\text { vasculitis, haemolytic anaemia, fever) and no } \\
\text { gastrointestinal activity }\end{array}$ & $1171(63.43 \%)$ \\
\hline $\begin{array}{l}\text { 2. No new features of lupus disease activity } \\
\text { compared to the previous assessment }\end{array}$ & $1574^{\mathrm{a}}(85.27 \%)$ \\
\hline $\begin{array}{l}\text { 3. SELENA-SLEDAI Physician Global Assessment } \\
(\text { PGA, scale } 0-3) \leq 1\end{array}$ & $1400(75.84 \%)$ \\
\hline \multicolumn{2}{|l|}{ Immunosuppressive medications } \\
\hline $\begin{array}{l}\text { 4. Current prednisolone (or equivalent) } \\
\text { dose } \leq 7.5 \mathrm{mg} \text { daily }\end{array}$ & $1258(68.15 \%)$ \\
\hline $\begin{array}{l}\text { 5. Well-tolerated standard maintenance doses } \\
\text { of immunosuppressive drugs and approved } \\
\text { biologic agents, excluding investigational drugs }{ }^{\mathrm{b}}\end{array}$ & 1838 (99.57 \%) \\
\hline All 5 criteria present & 810 (43.88 \%) \\
\hline
\end{tabular}

aased on flares (see "Methods"). ${ }^{\mathrm{b}}$ Calculated as not exceeding maximum recommended dose: hydroxychloroquine $\leq 400 \mathrm{mg}$; methotrexate $\leq 30 \mathrm{mg}$; azathioprine $\leq 200 \mathrm{mg}$; mycophenolate mofetil $\leq 3000 \mathrm{mg}$; mycophenolic acid $\leq 2160 \mathrm{mg}$; leflunomide $\leq 20 \mathrm{mg}$. SLE systemic lupus erythematosus, SELENA Safety of Estrogens in Lupus Erythematosus National Assessment trial, SLEDAI SLE disease activity index, CNS central nervous system, PGA Physician Global Assessment

\section{Discussion}

The authors have commenced a large prospective longitudinal study to validate the recently reported definition of LLDAS as being predictive of protection from damage accrual in SLE [11]. In the current crosssectional study of data collected at recruitment into this large multinational cohort, we have shown that $44 \%$ of patients with SLE met LLDAS criteria for low disease activity at a single point in time. This is the first multinational study to focus on the recent definition of LLDAS, and the frequency of LLDAS observed closely matches the $41 \%$ frequency of LLDAS attainment in our initial retrospective singlecentre validation study [11]. If LLDAS attainment or maintenance is shown to translate into improved patient outcomes, such as is the case for attainment of minimal disease activity in RA [9], this frequency of attainment, especially compared to more stringent cutoffs such as remission, suggests that LLDAS could represent a treatment target to use in SLE strategy trials and in clinical trials of novel therapies. Conversely, the fact that the majority of patients did not meet criteria for LLDAS speaks to the inadequate state of current treatment of SLE.

The definition of LLDAS [11] incorporates cutoffs for both disease activity and treatment burden. It refers to a desired clinical state, rather than a treatment response or change in disease activity, therefore representing a tool with which to stratify clinically diverse disease manifestations in a binary fashion, i.e. a patient is either in
LLDAS or not. LLDAS was designed to take into account validated measures of disease activity [20] and treatment variables, in view of the fact that treatment, especially with glucocorticoids, is known to contribute to poor long-term outcomes in SLE [21, 22]. In the current study, the second most frequent reason for not attaining LLDAS was glucocorticoid dose $>7.5 \mathrm{mg} /$ day. Although it is clear that higher disease activity over time is associated with worse outcomes [23], measures of disease activity alone, such as the SLEDAI-2 $\mathrm{K}$ or the British Isle Lupus Assessment Group (BILAG) measure, do not take into account treatment burden and therefore omit consideration of a major contributor to long-term harm in SLE. Similarly, measures of treatment response such as the SLE Responder Index [24], although they combine different measures of disease activity, do not represent a target state and do not include treatment variables.

Our finding that $99 \%$ of patients met at least one LLDAS criterion, but only $44 \%$ of patients met all five criteria, supports the value of including multiple variables in the definition of LLDAS. A higher proportion of patients achieved PGA $\leq 1$ than achieved SLEDAI $\leq 4$, potentially because of the inclusion of serological and clinical activity in the SLEDAI-2 K; the presence of dsDNA antibodies and hypocomplementaemia equates to 4 points on the SLEDAI- $2 \mathrm{~K}$, therefore any additional manifestation will result in the patient exceeding the SLEDAI-2 K cutoff for LLDAS.

The size of this cohort allowed us to evaluate factors associated with the presence of LLDAS. Some of the most common clinical manifestations of active disease in SLE are immunologic, cutaneous and renal disease [3], each of which was significantly negatively associated with LLDAS in multivariable regression. Disease duration of less than one year was also negatively associated with LLDAS, consistent with the observation that newly diagnosed patients are more likely to have active disease [18].

Our study has shed some further light on treatment practices in tertiary lupus centres. The lower frequency of use of immunosuppressants in this cohort may be related to issues with access to or availability of medications in some Asian countries, which has been previously described [26]; certainly in our recent single centre report based on an Australian cohort, the frequency of immunosuppressant use was considerably higher than in the present study [11]. The mean daily dose of prednisolone of $11 \mathrm{mg} /$ day is higher than doses reported in recent studies in single-centre cohorts with similar mean disease duration [11, 22]. As prolonged prednisolone use is known to contribute to significant morbidity in SLE [27], the consequences of high glucocorticoid dosing in this cohort 
Table 4 Determinants of lupus low disease activity state (LLDAS)

\begin{tabular}{|c|c|c|c|c|c|}
\hline \multirow[t]{2}{*}{ Independent variable } & \multirow[t]{2}{*}{ Number (\%) in LLDAS } & \multicolumn{2}{|c|}{ Univariable logistic regression for LLDAS } & \multicolumn{2}{|c|}{ Multivariable logistic regression for LLDAS } \\
\hline & & OR $(95 \% \mathrm{Cl})$ & $p$ & OR $(95 \% \mathrm{Cl})$ & $p$ \\
\hline \multicolumn{6}{|l|}{ Ethnicity $^{a}$} \\
\hline Caucasian & $63(50.00)$ & Reference & & Reference & \\
\hline Asian & $700(43.24)$ & $0.76(0.53-1.09)$ & 0.14 & $1.23(0.82-1.86)$ & 0.31 \\
\hline \multicolumn{6}{|l|}{ Gender } \\
\hline Female & $758(43.99)$ & Reference & & N/A & \\
\hline Male & $52(42.28)$ & $0.93(0.64-1.35)$ & 0.71 & & \\
\hline \multicolumn{6}{|l|}{ Education } \\
\hline Primary & $113(46.69)$ & Reference & & N/A & \\
\hline Secondary & $229(40.03)$ & $0.76(0.56-1.03)$ & 0.21 & & \\
\hline Tertiary & $254(41.10)$ & $0.80(0.59-1.07)$ & 0.30 & & \\
\hline \multicolumn{6}{|l|}{ Age at diagnosis } \\
\hline$>30$ years & $407(47.22)$ & Reference & & Reference & \\
\hline$\leq 30$ years & $397(40.80)$ & $0.77(0.64-0.93)$ & 0.006 & $0.86(0.70-1.06)$ & 0.16 \\
\hline \multicolumn{6}{|l|}{ Disease duration } \\
\hline$>1$ year & 765 (46.48) & Reference & & Reference & \\
\hline$\leq 1$ year & $34(22.82)$ & $0.34(0.23-0.51)$ & $<0.001$ & $0.31(0.19-0.49)$ & $<0.001$ \\
\hline \multicolumn{6}{|l|}{ Clinical features ${ }^{b}$} \\
\hline \multicolumn{6}{|l|}{ Malar rash } \\
\hline No & 331 (43.61) & Reference & & N/A & \\
\hline Yes & $479(44.07)$ & $1.02(0.82-1.23)$ & 0.85 & & \\
\hline \multicolumn{6}{|l|}{ Discoid rash } \\
\hline No & 701 (45.05) & Reference & & Reference & \\
\hline Yes & 109 (37.59) & $0.73(0.57-0.95)$ & 0.02 & $0.66(0.49-0.89)$ & 0.006 \\
\hline \multicolumn{6}{|l|}{ Photosensitive } \\
\hline No & $562(42.93)$ & Reference & & Reference & \\
\hline Yes & $248(46.18)$ & $1.14(0.93-1.40)$ & 0.20 & $1.18(0.93-1.50)$ & 0.16 \\
\hline \multicolumn{6}{|l|}{ Mouth Ulcers } \\
\hline No & $527(44.81)$ & Reference & & N/A & \\
\hline Yes & $283(42.24)$ & $0.90(0.74-1.09)$ & 0.28 & & \\
\hline \multicolumn{6}{|l|}{ Arthritis } \\
\hline No & $263(41.03)$ & Reference & & Reference & \\
\hline Yes & 547 (45.39) & $1.19(0.98-1.45)$ & 0.07 & $0.98(0.78-1.23)$ & 0.87 \\
\hline \multicolumn{6}{|l|}{ Serositis } \\
\hline No & $673(43.90)$ & Reference & & N/A & \\
\hline Yes & 137 (43.77) & $0.99(0.78-1.27)$ & 0.97 & & \\
\hline \multicolumn{6}{|l|}{ Renal } \\
\hline No & $508(48.71)$ & Reference & & Reference & \\
\hline Yes & 302 (37.61) & $0.63(0.53-0.77)$ & $<0.001$ & $0.60(0.48-0.75)$ & $<0.001$ \\
\hline \multicolumn{6}{|l|}{ Neurologic } \\
\hline No & 732 (43.42) & Reference & & Reference & \\
\hline Yes & $78(48.75)$ & $1.24(0.90-1.72)$ & 0.20 & $1.31(0.90-1.91)$ & 0.16 \\
\hline
\end{tabular}


Table 4 Determinants of lupus low disease activity state (LLDAS) (Continued)

\begin{tabular}{|c|c|c|c|c|c|}
\hline \multicolumn{6}{|l|}{ Haematologic } \\
\hline No & 289 (39.70) & Reference & & Reference & \\
\hline Yes & $521(46.60)$ & $0.22(0.03-1.76)$ & 0.09 & $1.21(0.97-1.51)$ & 0.09 \\
\hline \multicolumn{6}{|l|}{ Immunologic } \\
\hline No & $145(48.59)$ & Reference & & \multirow[t]{2}{*}{ N/A } & \\
\hline Yes & $665(42.99)$ & $0.80(0.63-1.03)$ & 0.08 & & \\
\hline \multicolumn{6}{|l|}{ ANA } \\
\hline No & $101(46.12)$ & Reference & & \multirow[t]{2}{*}{$\mathrm{N} / \mathrm{A}$} & \\
\hline Yes & 709 (43.58) & $0.90(0.68-1.20)$ & 0.48 & & \\
\hline \multicolumn{6}{|l|}{ Baseline damage } \\
\hline SLICC-DI = 0 & $505(44.84)$ & Reference & & \multirow[t]{2}{*}{$\mathrm{N} / \mathrm{A}$} & \\
\hline SLICC-DI >0 & 308 (42.95) & $1.00(0.83-1.21)$ & 0.96 & & \\
\hline \multicolumn{6}{|c|}{ Current high anti-dsDNA } \\
\hline No & $434(51.12)$ & Reference & & Reference & \\
\hline Yes & $341(36.43)$ & $0.55(0.46-0.68)$ & $<0.001$ & $0.65(0.53-0.81)$ & $<0.001$ \\
\hline \multicolumn{6}{|c|}{ Current low complement } \\
\hline No & $636(49.88)$ & Reference & & Reference & \\
\hline Yes & $142(29.83)$ & $0.45(0.37-0.55)$ & $<0.001$ & $0.52(0.40-0.67)$ & $<0.001$ \\
\hline $\mathrm{GDP} \leq \$ 25,000^{\mathrm{C}}$ & $324(36.00)$ & Reference & & Reference & \\
\hline GDP $>\$ 25,000$ & $486(51.37)$ & $1.89(1.56-2.26)$ & $<0.001$ & $1.57(1.25-1.98)$ & $<0.001$ \\
\hline \multicolumn{6}{|c|}{$\begin{array}{l}\text { Multivariable model choice - variables with a } p \text { value } \leq 0.20 \text { or clinical association in univariable regression were tested for multicolliniarity and confounding. } \\
\text { Final variable list - GDP (PPP) per capita, ethnicity, age at diagnosis, disease duration, discoid rash, photosensitivity, arthritis, renal disease, neurologic disease, } \\
\text { haematologic disease, dsDNA and complement. }{ }^{E} \text { Ethnicity }- \text { no significant differences were seen between Asian ethnicity subgroups. bever present, arthritis (two } \\
\text { or more joints with tenderness, swelling or effusion), serositis (pleuritis or pericarditis), renal disorder (persistent proteinuria }>0.5 \mathrm{~g} / \text { day, or presence of cellular } \\
\text { casts), neurologic disorder (seizures or psychosis not attributable to other causes), haematologic disorder (haemolytic anaemia, leukopenia, lymphopenia or } \\
\text { thrombocytopenia), immunologic criteria (presence of anti-dsDNA antibody, anti-Sm antibody, or positive finding of antiphospholipid antibodies). 'Countries with } \\
\text { GPD }<\$ 25,000 \text { - China, Indonesia, Malaysia, Philippines, Thailand; countries with GDP }>\$ 25,000 \text { - Australia, Hong Kong, Singapore, Taiwan. GDP measured in US } \\
\text { dollars. N/A variable not included in multivariable regression model } \\
\text { LLDAS lupus low disease activity state, SLICC Systemic Lupus International Collaborating Clinics, DI damage index, dsDNA double-stranded DNA, ANA antinuclear } \\
\text { antibody, GDP gross domestic product }\end{array}$} \\
\hline
\end{tabular}

with mean disease duration at recruitment close to 9 years will need to be further assessed.

It is well-established that personal socioeconomic status contributes to disease activity [28] and disease damage [29] in SLE. A recent study from the Asia Pacific region has also shown that national social wealth and development has a very strong association with 5-year survival among patients with SLE [25]. As such, we believed it important to include an index of socioeconomic wealth in analyzing predictors of LLDAS. Indeed, in our study, patients from countries with higher GDP per capita (PPP) were significantly more likely to meet all criteria for LLDAS. The GDP (PPP) per capita is adjusted for the cost of living and is therefore useful for comparing standards of living rather than just national wealth [19]. The main drawback of this measure is that it does not measure personal socioeconomic status, which would also vary from patient to patient. However, education level, a potential surrogate marker of individual socioeconomic standing, was not predictive of LLDAS.
Certain limitations apply to the current study. Because of the cross sectional nature of the current analysis, we are unable to ascertain whether time spent in LLDAS is associated with less damage accrual, as was shown in the original retrospective single-centre validation of LLDAS [11]. The cohort described here is the subject of a longitudinal study intended to determine the association of LLDAS attainment with outcomes including damage accrual. Additionally, the published definition of LLDAS requires the absence of new disease manifestations, which is not possible to measure in a cross-sectional study; we replaced this with a requirement for the absence of flare as measured using SFI, which is likely to have been more rather than less stringent. In addition, identification of the "well-tolerated immunosuppressive" component of LLDAS was modified due to the inability to determine dose change or tolerance at recruitment. This resulted in a high proportion of patients fulfilling this criterion, and use of the original definition in our longitudinal 
study may result in a lower overall frequency of LLDAS.

\section{Conclusions}

In conclusion, a validated definition of low disease activity has transformed both clinical care and clinical trial design in RA. Defining a treatment outcome that is attainable in an achievable proportion of patients and associated with improved long-term outcomes is something that has eluded SLE researchers until recently. Here, we have shown in a large multi-national and multi-ethnic cohort that LLDAS is attainable in a significant proportion of patients analysed at a single point in time, suggesting this definition is practical for use in long-term studies. We have also identified clinical variables associated with reduced likelihood of LLDAS, which if confirmed in longitudinal studies, may help with early identification of patients at higher risk. The next step in validation of LLDAS as an outcome measure in SLE is the definitive evaluation of whether LLDAS attainment or maintenance is associated with protection from long-term adverse outcomes such as damage accrual. This validation study, which will also allow for potential refinement of the LLDAS definition based on identifying variables that are most predictive of good outcomes, as was done for the recently described redefinition of remission in RA [30], is underway. That less than half of patients studied met the definition of LLDAS serves to underline the need for advances in the care of SLE, for which new strategies and new drugs are needed.

\section{Additional file}

Additional file 1: Table S1. Multiple logistic regression model properties. Table S2. Effect of disease manifestations and damage at recruitment on LLDAS components. (DOCX $59 \mathrm{~kb}$ )

\section{Abbreviations}

ACR: American College of Rheumatology; ANA: antinuclear antibody; APLC: Asia Pacific Lupus Collaboration; CNS: central nervous system; DI: Damage Index; dsDNA: double-stranded DNA; GDP: gross domestic product; LLDAS: lupus low disease activity state; PGA: Physician Global Assessment; RA: rheumatoid arthritis; ROC: receiver operating characteristic; SELENA: Safety of Estrogens in Lupus Erythematosus National Assessment; SFI: systemic lupus erythematosus flare index; SLE: systemic lupus erythematosus; SLEDAI: Systemic Lupus Erythematosus Disease Activity Index; SLICC: Systemic Lupus International Collaborating Clinics

\section{Acknowledgements}

Not applicable.

\section{Funding}

The Asia-Pacific Lupus Collaboration receives project support grants from GlaxoSmithKline, UCB and Janssen. Dr Golder holds a postgraduate scholarship from the National Health and Medical Research Council (NHMRC, APP1093545), Australia. Dr Nikpour holds an NHMRC research fellowship (APP1071735).

\section{Availability of data and material}

Reasonable requests to view the dataset used in this manuscript can be made in writing to the project manager for the Asia Pacific Lupus Collaboration - Dr Rangi Kandane-Rathnayake, rangi.kandane-rathnayake@monash.edu.

\section{Authors' contributions}

VG made substantial contributions to conception and design, acquisition of data, analysis and interpretation of data, drafting and revising the manuscript. RKR made substantial contributions to analysis and interpretation of data and revising the manuscript critically for important intellectual content. AYBH made substantial contributions to acquisition of data and revising the manuscript critically for important intellectual content. $\mathrm{MH}$ made substantial contributions to analysis and interpretation of data and revising the manuscript critically for important intellectual content. WL made substantial contributions to acquisition of data and revising the manuscript critically for important intellectual content. YA made substantial contributions to acquisition of data and revising the manuscript critically for important intellectual content. ZGL made substantial contributions to acquisition of data and revising the manuscript critically for important intellectual content. SFL made substantial contributions to acquisition of data and revising the manuscript critically for important intellectual content. SS made substantial contributions to acquisition of data and revising the manuscript critically for important intellectual content. CSL made substantial contributions to conception and design, acquisition of data and revising the manuscript critically for important intellectual content. ALL made substantial contributions to acquisition of data and revising the manuscript critically for important intellectual content. MYM made substantial contributions to acquisition of data and revising the manuscript critically for important intellectual content. AL made substantial contributions to acquisition of data and revising the manuscript critically for important intellectual content. KF made substantial contributions to acquisition of data and revising the manuscript critically for important intellectual content. SM made substantial contributions to acquisition of data and revising the manuscript critically for important intellectual content. STVN made substantial contributions to conception and design, acquisition of data and revising the manuscript critically for important intellectual content. LZ made substantial contributions to acquisition of data and revising the manuscript critically for important intellectual content. YJW made substantial contributions to acquisition of data and revising the manuscript critically for important intellectual content LH made substantial contributions to acquisition of data and revising the manuscript critically for important intellectual content. MC made substantial contributions to acquisition of data and revising the manuscript critically for important intellectual content. SON made substantial contributions to acquisition of data and revising the manuscript critically for important intellectual content. FG made substantial contributions to acquisition of data and revising the manuscript critically for important intellectual content. EFM made substantial contributions to conception and design, acquisition of data, analysis and interpretation of data and drafting and revising the manuscript. MN made substantial contributions to conception and design, acquisition of data, analysis and interpretation of data and drafting and revising the manuscript. All authors have given approval for the final version of the manuscript to be published. All authors have agreed to be accountable for all aspects of the work in ensuring that questions related to the accuracy or integrity of any part of the work are appropriately investigated and resolved.

\section{Competing interests}

The authors declare that they have no competing interests.

\section{Consent for publication}

Not applicable.

\section{Ethics approval and consent to participate}

Overarching ethics approval for data collection, analysis and publication of data collected by the Asia Pacific Lupus Collaboration was given by the Monash University Human Research Ethics Committee (Project Number: CF15/1617 - 2015000817)

\section{Author details}

${ }^{1}$ Monash University, Melbourne, Australia. ${ }^{2}$ The University of Melbourne, Melbourne, Australia. ${ }^{3}$ Chiang Mai University Hospital, Chiang Mai, Thailand ${ }^{4}$ People's Hospital Peking University Health Sciences Center, Beijing, China. 
${ }^{5}$ Chang Gung Memorial Hospital, Guishan Township, Taiwan. ${ }^{6}$ University of Malaya, Kuala Lumpur, Malaysia. 'University of Hong Kong, Hong Kong, Hong Kong. ${ }^{8}$ National University Hospital, Singapore, Singapore. ${ }^{9}$ Monash Health, Melbourne, Australia. ${ }^{10}$ University of Santo Tomas Hospital, Manila, Philippines. ${ }^{11}$ University of Padjadjaran, Bandung, Indonesia. ${ }^{12}$ Tan Tock Seng Hospital, Singapore, Singapore. ${ }^{13}$ University of New South Wales, Sydney, Australia. ${ }^{14}$ Royal Adelaide Hospital, Adelaide, Australia.

Received: 31 July 2016 Accepted: 24 October 2016

Published online: 09 November 2016

\section{References}

1. Sthoeger Z, Sharabi A, Mozes E. Novel approaches to the development of targeted therapeutic agents for systemic lupus erythematosus. J Autoimmun. 2014:54:60-71.

2. Ippolito A, Petri M. An update on mortality in systemic lupus erythematosus. Clin Exp Rheumatol. 2008;26:S72-79.

3. Nikpour M, Urowitz MB, Ibanez D, Gladman DD. Frequency and determinants of flare and persistently active disease in systemic lupus erythematosus. Arthritis Rheum. 2009;61:1152-8.

4. Petri M. Disease activity assessment in SLE: do we have the right instruments? Ann Rheum Dis. 2007;66:iii61-4.

5. Leone A, Sciascia S, Kamal A, Khamashta M. Biologicals for the treatment of systemic lupus erythematosus: current status and emerging therapies. Expert Rev Clin Immunol. 2015;11:109-16.

6. Franklyn K, Hoi A, Nikpour M, Morand EF. The need to define treatment goals for systemic lupus erythematosus. Nat Rev Rheumatol. 2014;10:567-71.

7. van Vollenhoven RF, Voskuyl A, Morand E, Aranow C. Remission in SLE: closing in on the target. Ann Rheum Dis. 2015;74:2103-6.

8. Steiman AJ, Urowitz MB, Ibanez D, Papneja A, Gladman DD. Prolonged clinical remission in patients with systemic lupus erythematosus. J Rheumatol. 2014;41:1808-16.

9. Khanna D, Oh M, Furst DE, Ranganath V, Gold RH, Sharp JT, Park GS, Keystone EC, Paulus HE. Evaluation of the preliminary definitions of minimal disease activity and remission in an early seropositive rheumatoid arthritis cohort. Arthritis Rheum. 2007:57:440-7.

10. van Vollenhoven RF, Mosca M, Bertsias G, Isenberg D, Kuhn A, Lerstrom K, Aringer M, Bootsma H, Boumpas D, Bruce IN, et al. Treat-to-target in systemic lupus erythematosus: recommendations from an international task force. Ann Rheum Dis. 2014;73:958-67.

11. Franklyn K, Lau CS, Navarra SV, Louthrenoo W, Lateef A, Hamijoyo L, Wahono CS, Chen SL, Jin O, Morton S, et al. Definition and initial validation of a Lupus Low Disease Activity State (LLDAS). Ann Rheum Dis. 2015;75:1651-21.

12. Hochberg MC. Updating the American College of Rheumatology revised criteria for the classification of systemic lupus erythematosus. Arthritis Rheum. 1997:40:1725.

13. Petri M, Orbai AM, Alarcon GS, Gordon C, Merrill JT, Fortin PR, Bruce IN, Isenberg D, Wallace DJ, Nived O, et al. Derivation and validation of the Systemic Lupus International Collaborating Clinics classification criteria for systemic lupus erythematosus. Arthritis Rheum. 2012;64:2677-86.

14. Australian Standard Classification of Cultural and Ethnic Groups, Second Edition. 2 edition. Australian Bureau of Statistics: Commonwealth of Australia; 2011.

15. Gladman DD, Ibanez D, Urowitz MB. Systemic lupus erythematosus disease activity index 2000. J Rheumatol. 2002;29:288-91.

16. Petri M, Buyon J, Kim M. Classification and definition of major flares in SLE clinical trials. Lupus. 1999;8:685-91.

17. Gladman DD, Goldsmith $\mathrm{CH}$, Urowitz MB, Bacon P. Fortin P, Ginzler E, Gordon C, Hanly JG, Isenberg DA, Petri M, et al. The Systemic Lupus International Collaborating Clinics/American College of Rheumatology (SLICC/ACR) Damage Index for Systemic Lupus Erythematosus International Comparison. J Rheumatol. 2000;27:373-6.

18. Urowitz MB, Gladman DD, Ibanez D, Fortin PR, Bae SC, Gordon C, Clarke A Bernatsky S, Hanly JG, Isenberg D, et al. Evolution of disease burden over five years in a multicenter inception systemic lupus erythematosus cohort. Arthritis Care Res (Hoboken). 2012;64:132-7.

19. World Economic Outlook Database. International Monetary Fund. 2015.

20. Strand V, Gladman D, Isenberg D, Petri M, Smolen J, Tugwell P. Outcome measures to be used in clinical trials in systemic lupus erythematosus. J Rheumatol. 1999;26:490-7.
21. Bruce IN, OKeeffe AG, Farewell V, Hanly JG, Manzi S, Su L, Gladman DD, Bae SC, Sanchez-Guerrero J, Romero-Diaz J, et al: Factors associated with damage accrual in patients with systemic lupus erythematosus: results from the Systemic Lupus International Collaborating Clinics (SLICC) Inception Cohort. Ann Rheum Dis. 2014;74;1706-13.

22. Ruiz-Arruza I, Ugarte A, Cabezas-Rodriguez I, Medina JA, Moran MA, Ruiz-Irastorza G. Glucocorticoids and irreversible damage in patients with systemic lupus erythematosus. Rheumatology (Oxford). 2014;53:1470-6.

23. Ibanez D, Gladman DD, Urowitz MB. Adjusted mean Systemic Lupus Erythematosus Disease Activity Index-2 K is a predictor of outcome in SLE. J Rheumatol. 2005:32:824-7.

24. Furie RA, Petri MA, Wallace DJ, Ginzler EM, Merrill JT, Stohl W, Chatham WW, Strand V, Weinstein A, Chevrier MR, et al. Novel evidence-based systemic lupus erythematosus responder index. Arthritis Rheum. 2009;61:1143-51.

25. Jakes RW, Bae SC, Louthrenoo W, Mok CC, Navarra SV, Kwon N. Systematic review of the epidemiology of systemic lupus erythematosus in the AsiaPacific region: prevalence, incidence, clinical features, and mortality. Arthritis Care Res (Hoboken). 2012;64:159-68.

26. Yap DY, Chan TM. Treatment of lupus nephritis: practical issues in Asian countries. Int J Rheum Dis. 2015;18:138-45.

27. Zonana-Nacach A, Barr SG, Magder LS, Petri M. Damage in systemic lupus erythematosus and its association with corticosteroids. Arthritis Rheum. 2000;43:1801-8.

28. Karlson EW, Daltroy LH, Lew RA, Wright EA, Partridge AJ, Fossel AH, Roberts WN, Stern SH, Straaton KV, Wacholtz MC, et al. The relationship of socioeconomic status, race, and modifiable risk factors to outcomes in patients with systemic lupus erythematosus. Arthritis Rheum. 1997;40:47-56.

29. Petri M, Purvey S, Fang H, Magder LS. Predictors of organ damage in systemic lupus erythematosus: the Hopkins Lupus Cohort. Arthritis Rheum. 2012;64:4021-8.

30. Felson DT, Smolen JS, Wells G, Zhang B, van Tuyl LH, Funovits J, Aletaha D, Allaart CF, Bathon J, Bombardieri S, et al. American College of Rheumatology/European League against Rheumatism provisional definition of remission in rheumatoid arthritis for clinical trials. Ann Rheum Dis. 2011; 70:404-13.

\section{Submit your next manuscript to BioMed Central and we will help you at every step:}

- We accept pre-submission inquiries

- Our selector tool helps you to find the most relevant journal

- We provide round the clock customer support

- Convenient online submission

- Thorough peer review

- Inclusion in PubMed and all major indexing services

- Maximum visibility for your research

Submit your manuscript at www.biomedcentral.com/submit
) Biomed Central 